\title{
Assessing invertebrate-mediated herbivory in canopies across a gradient of human-modified tropical forests
}

\author{
Julia Barreto $^{1}$, Erika Berenguer ${ }^{2}$, Joice Ferreira ${ }^{3}$, Carlos $\mathrm{Joly}^{4}$, Yadvinder Malhi ${ }^{2}$, Marina \\ de Seixas $^{3}$, and Jos Barlow ${ }^{1}$ \\ ${ }^{1}$ Universidade Federal de Lavras \\ ${ }^{2}$ University of Oxford \\ ${ }^{3}$ Embrapa Amazônia Oriental \\ ${ }^{4}$ State University of Campinas/UNICAMP
}

July 7,2020

\begin{abstract}
1. Studies on the effects of human-driven forest disturbance usually focus on either biodiversity or carbon dynamics but much less is known about ecosystem processes that integrate trophic levels. Herbivory is one fundamental ecological process for ecosystem functioning that remains underexplored and is poorly quantified in human-modified tropical rainforests. 2. Here, we present the results of the largest study to date on the impacts of human disturbances on herbivory. We quantified the incidence and severity of herbivory caused by chewers, miners and gall-formers in 199,869 canopy leaf blades from 1,102 trees distributed across 20 forest plots located along a gradient of human disturbance in the Amazon. 3. We found that chewers dominated herbivory incidence, yet were not a good predictor of the other forms of herbivory either at the stem or plot level. Herbivory severity was correlated with disturbance intensity, being greater at more disturbed sites. 4. Synthesis. Although our large-scale study of canopy herbivory in Amazonian forests suggests that human disturbance increases the severity of leaf herbivory, effects were weak. Additionally, we found no effect of human disturbance in incidence of leaf herbivory. These results combined indicate that herbivory is a relatively resilient process to human impacts.
\end{abstract}

\section{Hosted file}

herbivory_ms.docx available at https://authorea.com/users/339870/articles/467720-assessinginvertebrate-mediated-herbivory-in-canopies-across-a-gradient-of-human-modifiedtropical-forests 